\title{
Current State and Future Trends in Location Recommender Systems
}

\author{
Aysun Bozanta \\ Management Information Systems, Bogazici University, Istanbul, Turkey \\ E-mail: aysun.bozanta@boun.edu.tr \\ Birgul Kutlu \\ Management Information Systems, Bogazici University, Istanbul, Turkey \\ E-mail: birgul.kutlu@boun.edu.tr
}

\begin{abstract}
Technological developments in mobile devices enabled the utilization of geographical data for social networks. Accordingly, location-based social networks have become very attractive. The popularity of location-based social networks has prompted researchers to study recommendation systems for location-based services. There are many studies that develop location recommendation systems using various variables and algorithms. However, articles detailing past and present studies, and making future suggestions, are limited. Therefore, this study aims to thoroughly review the research performed on location recommender systems. For this purpose, topic pairs; "location and recommender system" and "location and recommendation system" were searched in the Web of Knowledge database. Resulting articles were examined in detail with respect to data sources and variables, algorithms, and evaluation techniques used. Thus, the current state of location recommender systems research is summarized and future recommendations are provided for researchers and developers. It is expected that the issues presented in this paper will advance the discussion of next generation location recommendation systems.
\end{abstract}

Index Terms-Location, Recommender System, Recommendation System.

\section{INTRODUCTION}

Recommender Systems (RSs) are personalized information agents which gather data on the preferences of its users for a set of items such as movies, songs, books, applications, websites, travel destinations etc. and generate appropriate suggestions [1][2][3]. RSs which are the most powerful and popular information discovery tools provide valuable support for their users to cope with information overload and help making better choices [4]. RSs have been studied both in the industry and academia over the last decade for various application areas.

Social networks have been increasingly used to manage various functions of daily lives such as communication, collaboration, and information sharing [5]. Mobile devices and GPS technology provide location and time information which enabled the emergence and extensive use of location-based services. Location-based services are valuable to users for finding the location of lost items or elderly family members having weak memory, or child security [6-69]. As, location-based social networks have become very attractive, there has been abundance of information available about locations and user preferences. Various location choices have become accessible for users and finding the best one meeting the requirements has become difficult. Those systems are rich data resources which can be mined and used for giving personalized recommendations [7] [8]. Therefore, Location Recommender Systems (LRSs) have begun to be developed and researched. There are many studies for LRS development using numerous methods. However, even with all those developments, the current state of LRSs still require further improvements to make recommendation methods more effective and efficient. Therefore, this study aims to depict the current state of LRSs, identify their limitations and present suggestions for future research.

The rest of the paper is organized as follows: Section II explores related works of location recommender systems. Section III describes the methods used for LRS development. Results are presented in section IV by subsections: data sources and variables, algorithms, and evaluation techniques. Finally, the conclusion is given in section $\mathrm{V}$ together with future research directions.

\section{RELATED WORKS}

Recommender systems are popular both commercially and academically. They can now be found in many applications that expose the user to huge collections of items.

Recommendation systems have been applied on various domains such as product [9], movie [10], music [11], and book [12]. Location recommendation systems have also become popular after location-based social networks have emerged. Location-based social networks allow users to "check-in" at some venues and rate their visits. By using the information that users have shared, related location recommendations are presented to the users.

There are various location recommendation systems 
which use different data sets and algorithms in the literature. These algorithms are generally divided into two: algorithms that utilize collaborative filtering and algorithms that utilize content based filtering. Collaborative filtering establishes that personal recommendations can be computed by calculating the similarity between one user's preferences and the preferences of other individuals [13]. On the other hand, content-based filtering utilizes the information about an item itself for recommendations [13]. Moreover, hybrid composites of collaborative and content-based filtering have recently been awarded for their ability to improve rating prediction [14]. However, those approaches ignore contextual information such as time, weather, etc. In context-aware recommendation systems, user preferences for items are not only a function of items themselves, but also a function of the context in which items are being considered [15].

In addition, there are studies surveying location recommendation systems whose content, coverage and time span is different than this study [13][16][17][18].

\section{METHOD}

This study aims to review the research performed on LRSs and to propose influential suggestions for future research. Based on the research objective defined, it was aimed to produce an updated snapshot of the existing knowledge relevant to LRSs.

There are many different databases available for searching scholarly articles and it is important that the appropriate databases are included. For this purpose, Web of Knowledge, which provides the most reliable, integrated, multidisciplinary research connected through linked content citation metrics from multiple sources within a single database, was chosen.

The search was conducted from 1945 to the end of 2015, without resource type limitation. Topic pairs; "location and recommender system" and "location and recommendation system" were searched in the topic of the Web of Knowledge database yielding 86 and 115 results respectively.

First elimination was executed by disregarding the patents, inaccessible articles and titles that exist on both result sets. After the first elimination, 140 articles remained.

The second elimination phase entailed reviewing of the abstracts and excluding irrelevant studies. For this purpose, systems that do not recommend location, places or venues were excluded. This elimination resulted in a total of 55 articles.

Consequently, those articles were examined in detail with respect to research methods applied, data sources, variables, algorithms and evaluation techniques used.

\section{RESULTS}

Although the roots of recommender systems hold on to the past research, these systems emerged as an independent research area in the mid-1990s [19]. On the other hand, the emergence of location-based recommender systems depends on the increasing ubiquity of internet-accessing smart devices. Accordingly, research on LRSs have been increasing and this growth has been accelerated after 2010 (Fig.1).

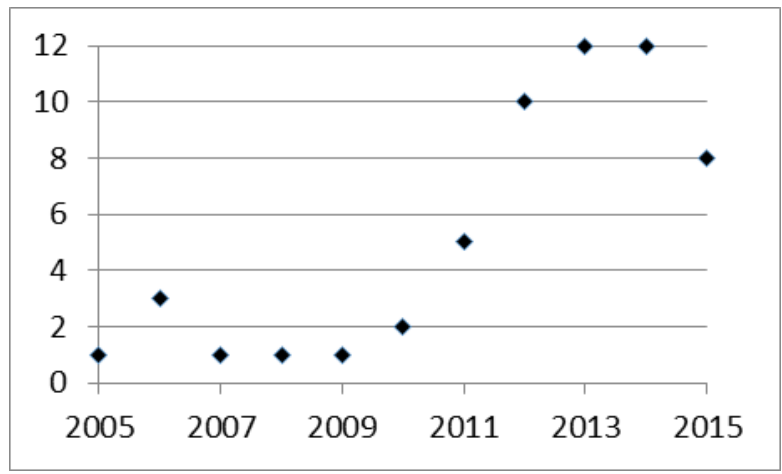

Fig.1. Frequency of papers according to publishing years

This increase can be explained by the launch of location-based social network applications such as Gowalla (2007) and Foursquare (2009). In 2009, Foursquare for developers was announced and various APIs were shared with users. In 2012, Gowalla went out of business and its data have become publicly available. Afterwards, those APIs and datasets have been started to be used by researchers for data collection and analysis. Eventually the studies have been slightly decreased due to the changes in terms and conditions.

Regarding the articles examined in this study, out of 55 researches, only 3 of them proposed a framework, 2 of them presented prototypes and remaining 50 focused on improving existing algorithms. The detailed evaluation of those 55 articles will be given in next subsections.

\section{A. Data Sources and Variables}

Data sources and variables that were used, respective years and references are presented in Table 1.

The mostly used data sources are Foursquare which is used by 50 million people each month and 8 billion check-ins were made until now [20], and Flicker which is one of the mostly used photo sharing applications including 15 billion photos uploaded by users [21].

Although, user rating is the mostly used variable in literature contextual variables were also emphasized. It is observed that friendship, time, and review/tips were the mostly utilized variables. 
Table 1. Data Sources and Variables

\begin{tabular}{|c|c|c|c|}
\hline Data Sources & Variables & Year & Reference \\
\hline \multirow{4}{*}{ Foursquare } & category & 2013 & {$[22]$} \\
\hline & $\begin{array}{c}\text { Tips, mayor, to-do } \\
\text { list, user's friend } \\
\text { list }\end{array}$ & $\begin{array}{l}2012 \\
2014\end{array}$ & {$[23][24]$} \\
\hline & $\begin{array}{l}\text { social relations, } \\
\text { ratings, distances }\end{array}$ & $\begin{array}{l}2014, \\
2015\end{array}$ & {$[25][26]$} \\
\hline & tips & 2015 & [27] \\
\hline \multirow[b]{2}{*}{ Flickr } & Weather, time & $\begin{array}{l}2013, \\
2015\end{array}$ & {$[28][29]$} \\
\hline & $\operatorname{tag}$ & $\begin{array}{l}2010, \\
2014, \\
2015\end{array}$ & $\begin{array}{c}{[29][30]} \\
{[31][32][33]}\end{array}$ \\
\hline Naver Map & $\begin{array}{l}\text { location, time, } \\
\text { weather }\end{array}$ & 2007 & [34-42] \\
\hline $\begin{array}{c}\text { Yahoo Life } \\
\text { Plus, } \\
\text { Panoramio }\end{array}$ & $\begin{array}{l}\text { keyword, map, } \\
\text { time sequence, } \\
\text { category, image }\end{array}$ & $\begin{array}{l}2009, \\
2014\end{array}$ & {$[35][36]$} \\
\hline LION Travel & $\begin{array}{c}\text { gender, } \\
\text { age,constellations, } \\
\text { selling place, }\end{array}$ & 2011 & {$[37]$} \\
\hline pin@clip & distance, time & 2011 & {$[38]$} \\
\hline GPS Data & $\begin{array}{l}\text { the sequence of } \\
\text { movements, the } \\
\text { visited popularity, } \\
\text { the hierarchical } \\
\text { property of } \\
\text { location }\end{array}$ & $\begin{array}{l}2011, \\
2012\end{array}$ & {$[39][40]$} \\
\hline GSM & trajectory & 2012 & [41] \\
\hline Zomato & $\begin{array}{l}\text { Affordability, } \\
\text { Cuisine- } \\
\text { Preference, } \\
\text { Vegan-Factor, } \\
\text { Reputation of } \\
\text { Item } \\
\end{array}$ & 2014 & {$[42]$} \\
\hline Jie Pang & $\begin{array}{l}\text { time, location, } \\
\text { category, } \\
\text { popularity of } \\
\text { location }\end{array}$ & 2014 & [43] \\
\hline Gowalla & $\begin{array}{l}\text { friendship, date } \\
\text { and time, latitude } \\
\text { and longitude }\end{array}$ & 2015 & {$[44][45]$} \\
\hline Facebook & $\begin{array}{l}\text { gender, race, age, } \\
\text { and travel season }\end{array}$ & 2015 & {$[32]$} \\
\hline Geosocial2 & $\begin{array}{l}\text { friendship, date } \\
\text { and time, latitude } \\
\text { and longitude }\end{array}$ & 2015 & [44] \\
\hline $\begin{array}{l}\text { google+, } \\
\text { Yelp, Qype }\end{array}$ & review & 2015 & [46] \\
\hline
\end{tabular}

\section{B. Algorithms}

Algorithms used in academic research are presented in Table 2. with respect to publication years.

Table 2. Algorithms

\begin{tabular}{|c|c|c|}
\hline Algorithm & Year & Reference \\
\hline Association Rule Mining & 2005 & {$[47]$} \\
\hline Decision Tree & 2006 & {$[48]$} \\
\hline & 2006,2 & \\
& 011, & {$[49][50][51]$} \\
Collaborative Filtering (CF) & 2012,2 & {$[52][53]$} \\
& 013 & \\
\hline & 2006, & \\
& 2008, & {$[23][24][37]$} \\
& 2011, & {$[50][54][55]$} \\
& 2012, & \\
\hline & 2013, & \\
\hline
\end{tabular}

\begin{tabular}{|c|c|c|}
\hline & 2014 & \\
\hline Bayesian Network & 2007 & [34] \\
\hline $\begin{array}{l}\text { Mean-shift based GPS } \\
\text { Clustering } \\
\end{array}$ & 2010 & [30] \\
\hline Behavioral Cost-Benefit Anal. & 2011 & [38] \\
\hline CF with using HGSM & 2011 & [39] \\
\hline Hybrid Method & $\begin{array}{l}2011, \\
2012, \\
2015 \\
\end{array}$ & $\begin{array}{c}{[37][56][57]} \\
{[58][59]}\end{array}$ \\
\hline $\begin{array}{c}\text { Tree Algorithms: LZ, LeZi } \\
\text { Update and Active LeZi }\end{array}$ & 2012 & [41] \\
\hline $\begin{array}{l}\text { Ranking-based collective tensor } \\
\text { and matrix factorization model }\end{array}$ & 2012 & {$[40]$} \\
\hline Artificial Neural Network & $\begin{array}{l}2012, \\
2013\end{array}$ & {$[60][61]$} \\
\hline Sequential Pattern Mining & 2013 & [62] \\
\hline $\begin{array}{c}\text { Multinomial Bernoulli model of } \\
\text { Naive Bayesian }\end{array}$ & 2013 & [22] \\
\hline $\begin{array}{c}\text { Learning Automata based } \\
\text { Sentiment Analysis }\end{array}$ & 2013 & [27] \\
\hline $\begin{array}{c}\text { A* algorithm and genetic } \\
\text { algorithm }\end{array}$ & 2013 & [63] \\
\hline $\begin{array}{c}\text { Location-Aware and } \\
\text { Preference-Aware Clustering }\end{array}$ & 2013 & [25] \\
\hline $\begin{array}{l}\text { location-aware reputation based } \\
\text { collaborative filtering (LRCF) }\end{array}$ & 2014 & [42] \\
\hline $\begin{array}{c}\text { Multi-dimensional index, aR- } \\
\text { Tree }\end{array}$ & 2014 & [64] \\
\hline $\begin{array}{c}\text { Random Walk with Restart } \\
\text { (RWR) }\end{array}$ & 2014 & [31] \\
\hline SlopeOne Algorithm & 2014 & [65] \\
\hline $\begin{array}{c}\text { User partitioning and travel } \\
\text { penalty techniques }\end{array}$ & 2014 & [24] \\
\hline Context-Aware Techniques & $\begin{array}{l}2006, \\
2012, \\
2013, \\
2015\end{array}$ & $\begin{array}{c}{[26][28][29]} \\
{[33][48][51]} \\
{[56][58][60]} \\
{[61][66][67]} \\
{[68][69]}\end{array}$ \\
\hline LA, LCA-LDA and TA & $\begin{array}{l}2014, \\
2015\end{array}$ & [26][45] \\
\hline Naïve Bayesian & 2015 & [32] \\
\hline Author topic model-based CF & 2015 & [70] \\
\hline PLSA topic model & 2015 & [33] \\
\hline $\begin{array}{c}\text { Algorithm based on fluency } \\
\text { heuristic }\end{array}$ & 2015 & [46] \\
\hline $\begin{array}{c}\text { Higher-order singular value } \\
\text { decomposition }\end{array}$ & 2015 & [44] \\
\hline Kernel Density Estimation & 2015 & [29] \\
\hline Crowdsourcing & 2014 & [71] \\
\hline
\end{tabular}

The mostly utilized algorithms are collaborative filtering and content based filtering [72].

In collaborative filtering, personal recommendations can be computed by calculating the similarity between one user's preferences and the preferences of other individuals. In this type of filtering the preferences of a large user group are recorded. Given a user that is seeking recommendations, similarity metrics are utilized to find a subgroup of people that present preferences similar to that user. Afterwards, average of the preferences of that subgroup is computed [73]. A key advantage of the collaborative filtering approach is that it does not rely on machine analyzable content and therefore it is capable of accurately recommending complex items such as movies without requiring an "understanding" of the item itself. However, collaborative filtering approaches often suffer from three problems: cold start, scalability, and sparsity 
[74]. On the other hand, content-based filtering utilizes the information about an item for recommendations. The advantage of this method is that it is not limited to suggesting options that have previously been rated by the users. These characteristics remove the cold-start problem of collaborative filtering approach. Furthermore content based filtering can provide the user with a better explanation as to why option $\mathrm{X}$ was suggested.

Content based filtering recommendation algorithms hold a set of items denoting the user's preferences. The task of the algorithm is to classify an unseen item (an option the user has not expressed any opinion about), as something relevant or irrelevant for the user [73-66]. Moreover, hybrid composites of collaborative and content-based filtering have recently been valued for their ability to improve rating prediction.

Context-Aware Recommender Systems (CARS), which deal with modeling and predicting the user tastes and preferences by incorporating available contextual information into the recommendation process as explicit additional categories of data.

Recently, hybrid methods and context-aware techniques have been intensively used for location recommender systems. It is obvious that using contextual information increases the power of recommending more relevant items to the users.

Although, users' preferences and venue characteristics were considered as the necessary input data for building recommender systems, there is increasing attention to temporal features of the data and the social network links between users.

\section{Evaluation Techniques}

A crucial step of all recommender system research is choosing a right methodology to evaluate the quality of the recommendations.

Evaluation metrics that have been used for location recommender systems, respective years and references are presented in Table 3.

Precision and recall are the most frequent metrics that are used for the evaluation of LRSs together with Mean Absolute Error (MAE).

Table 3. Evaluation Techniques

\begin{tabular}{|c|c|c|}
\hline Evaluation Metric & Year & Reference \\
\hline Precision & $\begin{array}{l}2006, \\
2009, \\
2010, \\
2013, \\
2014, \\
2015\end{array}$ & $\begin{array}{c}{[25][26][28][30]} \\
{[31][33][35][42]} \\
{[50][54][70][75][76]}\end{array}$ \\
\hline Recall & $\begin{array}{l}2006, \\
2010, \\
2013, \\
2014, \\
2015\end{array}$ & $\begin{array}{l}{[25][26][31][42]} \\
{[50][54][70][76]}\end{array}$ \\
\hline $\begin{array}{c}\text { Mean Absolute Error } \\
\text { (MAE) }\end{array}$ & $\begin{array}{l}2006, \\
2012, \\
2013 \\
2014\end{array}$ & $\begin{array}{c}{[44][48][55][60]} \\
{[65][75][77]}\end{array}$ \\
\hline $\begin{array}{c}\text { Mean Average Precision } \\
\text { (MAP) }\end{array}$ & $\begin{array}{l}2011 \\
2013 \\
2015\end{array}$ & {$[28][29][33][39]$} \\
\hline
\end{tabular}

\begin{tabular}{|c|c|c|}
\hline F-Measure & 2013, & {$[42][50][75]$} \\
\hline E-Measure & 2014 & {$[50]$} \\
\hline k-value & 2014 & {$[64]$} \\
\hline Benefit Ratio & 2013, & {$[28][33]$} \\
\hline Execution time & 2015 & 2013, \\
\hline Error Rate & 2011, & {$[24][27][64][65]$} \\
\hline $\begin{array}{c}\text { Root mean squared error } \\
\text { (RMSE) }\end{array}$ & 2012, & {$[37][78]$} \\
\hline $\begin{array}{c}\text { Normal Mean Absolute } \\
\text { Error (NMAE) }\end{array}$ & 2013, & {$[40][44][55][60]$} \\
\hline RAE, RRSE & 2013 & {$[55]$} \\
\hline hit rate and resource & 2013 & {$[60]$} \\
\hline consumption & 2012 & {$[41]$} \\
\hline NDCG & 2011 & {$[39]$} \\
\hline User evaluation & 2011, & {$[51][43]$} \\
\hline
\end{tabular}

\section{CONCLUSION}

In the last decade, location-aware recommendation approaches made an important progress with the new systems and academic research. However, there are still unsolved problems and needs for more effective recommendations.

In this study, the existing literature have been reviewed comprehensively for location recommender systems. The data sources and variables that have been used, algorithms that have been applied, and the evaluation techniques have been examined.

The current state of LRSs has been presented by examining 55 articles from Web of Knowledge database. Further research recommendations for data and variable use, algorithms and evaluation techniques are summarized in next subsections.

\section{A. Future Research Directions}

This study presents the current state of location recommender systems and discusses future perspectives. These perspectives include the incorporation of contextual information into the recommendation process, personalization with different techniques such as gathering user's priorities, using more user-related information (age, gender, etc.), integration of social network analysis in recommendation process, using different techniques for evaluation:

- The importance of contextual variables such as traffic conditions, weather, time, time sequence, visit length, visit rhythm, is noticed by the researchers [26] [28] [29] [33] [48] [51] [56] [60] [61] [66] [67] [68] [69]. However, both the addition method (pre-filtering, post-filtering etc.) and the discretization of those variables still require further research [28] [48] [79].

- Personalization is crucial for effective LRS [47-44] so user-related variables such as age, gender, race should be included [33]. 
- Gathering user priorities for each criterion may provide more effective and personalized LRSs [76].

- Social network analysis may be very beneficial in order to predict user preferences [60] [80]. Community detection may be very helpful for the problems of traditional approaches such as cold start, etc.

- Energy consumption depending on the processing time should be decreased with better algorithms [41].

- Evaluation of LRSs has been made by using metrics which are generally used for datamining. However, researches that measure the performance of LRSs and the adoption of users are very limited. User surveys can be used for gathering users' feedback and measuring their satisfaction levels [34] [43] [51] [66].

- Moreover, the datasets used for evaluation are usually still the same datasets used to evaluate traditional recommendation systems. Dynamic real time data can be used for evaluation.

\section{B. Limitations}

The main limitations of this study can be the number of keywords that are used to search related articles and the usage of one data source - Web of Knowledge. The cover of this literature review may be improved by increasing the number of keywords and using different databases.

In spite of the limitations, the authors expect that the issues presented in this paper will advance the discussion of next generation location recommendation systems.

\section{ACKNOWLEDGEMENT}

This study was supported by the Bogazici University Scientific Research Projects Fund (Project \#11463).

\section{REFERENCES}

[1] Burke, R. (2002). Hybrid recommender systems: Survey and experiments. User Modeling and User-adapted Interaction, 12(4), 331-370.

[2] Burke, R. (2007). Hybrid web recommender systems. In The Adaptive Web (pp. 377-408). Springer Berlin Heidelberg.

[3] Bobadilla, J., Ortega, F., Hernando, A., \& Gutiérrez, A. (2013). Recommender systems survey. Knowledge-Based Systems, 46, 109-132.

[4] Ricci, F., Rokach, L., \& Shapira, B. (2011). Introduction to recommender systems handbook (pp. 1-35). Springer US.

[5] Schall, D. (2015). Social Network-based Recommender Systems. Springer.

[6] Bhatia, S., (2016). "Design and Development of New Application for Mobile Tracking", International Journal of Information Technology and Computer Science (IJITCS), Vol.8, No.11, pp.54-60, 2016. DOI: 10.5815/ijitcs.2016.11.07

[7] Marinho, L. B., Hotho, A., Jäschke, R., Nanopoulos, A., Rendle, S., Schmidt-Thieme, L., \& Symeonidis, P. (2012). Recommender systems for social tagging systems. Springer Science \& Business Media.

[8] Pu, Q., Lbath, A., \& He, D. (2012). Location based recommendation for mobile users using language model and skyline query. International Journal of Information Technology and Computer Science (IJITCS), 4(10), 19.

[9] Schafer, J. B., Konstan, J., \& Riedl, J. (1999, November). Recommender systems in e-commerce. In Proceedings of the 1st ACM conference on Electronic commerce (pp. 158166). ACM.

[10] Jadhav, S.L., Mali, M.P., (2016). "Pre-Recommendation Clustering and Review Based Approach for Collaborative Filtering Based Movie Recommendation", International Journal of Information Technology and Computer Science (IJTCS), Vol.8, No.7, pp.72-80. DOI: 10.5815/ijitcs.2016.07.10

[11] Celma, O. (2010). Music recommendation. In Music Recommendation and Discovery (pp. 43-85). Springer Berlin Heidelberg.

[12] Gil, J. M., Lim, J., \& Seo, D. M. (2016). Design and Implementation of MapReduce-Based Book Recommendation System by Analysis of Large-Scale BookRental Data. In Advanced Multimedia and Ubiquitous Engineering (pp. 713-719). Springer Singapore.

[13] Bao, J., Zheng, Y., Wilkie, D., \& Mokbel, M. (2015). Recommendations in location-based social networks: a survey. Geoinformatica, 19(3), 525-565.

[14] Burke, R. (2002). Hybrid recommender systems: Survey and experiments. User modeling and user-adapted interaction, 12(4), 331-370.

[15] Adomavicius, G., \& Tuzhilin, A. (2011). Context-aware recommender systems. In Recommender systems handbook (pp. 217-253). Springer US.

[16] Ricci, F. (2010). Mobile recommender systems. Information Technology \& Tourism, 12(3), 205-231.

[17] Felfernig, A., Gordea, S., Jannach, D., Teppan, E., \& Zanker, M. (2007). A short survey of recommendation technologies in travel and tourism. OEGAI Journal, 25(7), 17-22.

[18] Bao, J., Zheng, Y., Wilkie, D., \& Mokbel, M. F. (2013). A survey on recommendations in location-based social networks. ACM Transaction on Intelligent Systems and Technology.

[19] Adomavicius, G., \& Tuzhilin, A. (2005). Toward the next generation of recommender systems: A survey of the stateof-the-art and possible extensions. IEEE transactions on knowledge and data engineering, 17(6), 734-749.

[20] About, (2016). About Foursquare. Accessed at April 20, 2016 from https://tr.foursquare.com/about

[21] Fan, B. (2015). New Flickr App Offers $360^{\circ}$ Photo Experience via Samsung Gear VR Powered By Oculus. Accessed at April 20, 2016 from http://blog.flickr.net/en/2015/12/09/new-flickr-app-offers360-photo-experience-via-samsung-gear-vr-powered-byoculus/

[22] Gupta, A., \& Singh, K. (2013, August). Location based personalized restaurant recommendation system for mobile environments. In Advances in Computing, Communications and Informatics (ICACCI), International Conference, 507511. IEEE.

[23] Dhake, B., Lomte, S.S., Auti, R. A., Nagargoje, Y.R., \& Patil, B. (2014). LARS: An Efficient and Scalable LocationAware. International Journal Of Scientific Research And Education, 2(11).

[24] Sarwat, M., Levandoski, J. J., Eldawy, A., \& Mokbel, M. F. (2014). LARS*: An efficient and scalable location-aware recommender system. Knowledge and Data Engineering, IEEE Transactions on, 26(6), 1384-1399.

[25] Wang, H., Li, G., \& Feng, J. (2014). Group-Based Personalized Location Recommendation on Social Networks. In Web Technologies and Applications, 68-80. Springer International Publishing. 
[26] Yin, H., Cui, B., Sun, Y., Hu, Z., \& Chen, L. (2014). LCARS: A spatial item recommender system. ACM Transactions on Information Systems (TOIS), 32(3), 11.

[27] Krishna, P. V., Misra, S., Joshi, D., \& Obaidat, M. S. (2013, May). Learning automata based sentiment analysis for recommender system on cloud. In Computer, Information and Telecommunication Systems (CITS), International Conference, 1-5. IEEE.

[28] Majid, A., Chen, L., Chen, G., Mirza, H. T., Hussain, I., \& Woodward, J. (2013). A context-aware personalized travel recommendation system based on geotagged social media data mining. International Journal of Geographical Information Science, 27(4), 662-684.

[29] Memon, I., Chen, L., Majid, A., Lv, M., Hussain, I., \& Chen, G. (2015). Travel recommendation using geo-tagged photos in social media for tourist. Wireless Personal Communications, 80(4), 1347-1362.

[30] Cao, L., Luo, J., Gallagher, A. C., Jin, X., Han, J., \& Huang, T. S. (2010, March). A worldwide tourism recommendation system based on geotaggedweb photos. In ICASSP (pp. 2274-2277).

[31] Guo, L., Shao, J., Tan, K.L., \& Yang, Y. (2014, July). Wheretogo: Personalized travel recommendation for individuals and groups. In Mobile Data Management, IEEE 15th International Conference, 1, 49-58.

[32] Subramaniyaswamy, V., Vijayakumar, V., Logesh, R., \& Indragandhi, V. (2015). Intelligent Travel Recommendation System by Mining Attributes from Community Contributed Photos. Procedia Computer Science, 50, 447-455.

[33] Xu, Z., Chen, L., \& Chen, G. (2015). Topic based contextaware travel recommendation method exploiting geotagged photos. Neurocomputing, 155, 99-107.

[34] Park, M. H., Hong, J. H., \& Cho, S. B. (2007). Locationbased recommendation system using bayesian user's preference model in mobile devices. In Ubiquitous Intelligence and Computing (pp. 1130-1139). Springer Berlin Heidelberg.

[35] Kuo, M. H., Chen, L. C., \& Liang, C. W. (2009). Building and evaluating a location-based service recommendation system with a preference adjustment mechanism. Expert Systems with Applications, 36(2), 3543-3554.

[36] Shimada, K., Uehara, H., \& Endo, T. (2014, August). A comparative study of potential-of-interest days on a sightseeing spot recommender. In Advanced Applied Informatics (IIAIAAI), IIAI 3rd International Conference, 555-560.

[37] Shih, D. H., Yen, D. C., Lin, H. C., \& Shih, M. H. (2011). An implementation and evaluation of recommender systems for traveling abroad. Expert Systems with Applications, 38(12), 15344-15355.

[38] Aihara, K., Koshiba, H., \& Takeda, H. (2011). Behavioral cost-based recommendation model for wanderers in town. In Human-Computer Interaction. Towards Mobile and Intelligent Interaction Environments (pp. 271-279). Springer Berlin Heidelberg.

[39] Zheng, Y., Zhang, L., Ma, Z., Xie, X., \& Ma, W. Y. (2011). Recommending friends and locations based on individual location history. ACM Transactions on the Web (TWEB), 5(1), 5.

[40] Zheng, V. W., Zheng, Y., Xie, X., \& Yang, Q. (2012). Towards mobile intelligence: Learning from GPS history data for collaborative recommendation. Artificial Intelligence, 184, 17-37.

[41] Rodriguez-Carrion, A., Garcia-Rubio, C., Campo, C., Cortés-Martín, A., Garcia-Lozano, E., \& Noriega-Vivas, P. (2012). Study of LZ-Based location prediction and its application to transportation recommender systems.
Sensors, 12(6), 7496-7517.

[42] Bedi, P., Agarwal, S. K., Sharma, S., \& Joshi, H. (2014, September). SAPRS: Situation-Aware Proactive Recommender system with explanations. In Advances in Computing, Communications and Informatics (ICACCI, 2014 International Conference on (pp. 277-283). IEEE.

[43] Yu, Z., Feng, Y., Xu, H., \& Zhou, X. (2014). Recommending travel packages based on mobile crowdsourced data. Communications Magazine, IEEE, 52(8), 56-62.

[44] Sattari, M., Toroslu, I. H., Karagoz, P., Symeonidis, P., \& Manolopoulos, Y. (2015). Extended feature combination model for recommendations in location-based mobile services. Knowledge and Information Systems, 44(3), 629661.

[45] Yin, H., Cui, B., Chen, L., Hu, Z., \& Zhang, C. (2015). Modeling location-based user rating profiles for personalized recommendation. ACM Transactions on Knowledge Discovery from Data (TKDD), 9(3), 19.

[46] Mordacchini, M., Passarella, A., Conti, M., Allen, S. M., Chorley, M. J., Colombo, G. B., ... \& Whitaker, R. M. (2015). Crowdsourcing through Cognitive Opportunistic Networks. ACM Transactions on Autonomous and Adaptive Systems (TAAS), 10(2), 13.

[47] Saraee, M., Khan, S., \& Yamaner, S. (2005). Data mining approach to implement a recommendation system for electronic tour guides. In Proceedings of The 2005 International Conference on E-Business, Enterprise Information Systems, E-Government, and Outsourcing, EEE 2005, Las Vegas, Nevada, USA, June 20-23, 2005 (pp. 215218). CSREA Press.

[48] Lee, B. H., Kim, H. N., Jung, J. G., \& Jo, G. S. (2006, September). Location-based service with context data for a restaurant recommendation. In Database and Expert Systems Applications (pp. 430-438). Springer Berlin Heidelberg.

[49] Horozov, T., Narasimhan, N., \& Vasudevan, V. (2006, January). Using location for personalized POI recommendations in mobile environments. In Applications and the Internet, 2006. SAINT 2006. International Symposium on (pp. 6-pp). IEEE.

[50] Huang, C. C., Manh, H. N., \& Hwang, T. H. (2013, December). Vehicle trajectory prediction across nonoverlapping camera networks. In Connected Vehicles and Expo (ICCVE), 2013 International Conference on (pp. 375380). IEEE.

[51] Gavalas, D., \& Kenteris, M. (2011). A web-based pervasive recommendation system for mobile tourist guides. Personal and Ubiquitous Computing, 15(7), 759-770.

[52] Lu, E. H. C., Ying, J. J. C., Chen, H. S., Lin, K. W., Tseng, V. S., Tsai, H. W., ... \& Lin, S. C. (2012, August). Simulation framework for travel trajectory generation and mobile transaction modeling. In Information Security and Intelligence Control (ISIC), 2012 International Conference on (pp. 115-118). IEEE.

[53] Hasegawa, T., \& Hayashi, T. (2013, June). Collaborative filtering based spot recommendation seamlessly available in home and away areas. In Computer and Information Science (ICIS), 2013 IEEE/ACIS 12th International Conference on (pp. 547-548). IEEE.

[54] Takeuchi, Y., \& Sugimoto, M. (2006). CityVoyager: an outdoor recommendation system based on user location history. In Ubiquitous intelligence and computing (pp. 625636). Springer Berlin Heidelberg.

[55] Li, E., Chen, X., Hao, T., \& Fu, X. (2013, July). Research on LBS-based Optimizing Personal Recommendation System. In 2nd International Conference on Advances in Computer Science and Engineering (CSE 2013). Atlantis Press. 
[56] Barranco, M. J., Noguera, J. M., Castro, J., \& Martínez, L. (2012). A context-aware mobile recommender system based on location and trajectory. In Management intelligent systems (pp. 153-162). Springer Berlin Heidelberg.

[57] MARTINEZ, L. (2012). A location-aware tourism recommender system based on mobile devices. In Uncertainty Modeling in Knowledge Engineering and Decision Making: Proceedings of the 10th International FLINS Conference, Istanbul, Turkey, 26-29 August 2012 (Vol. 7, p. 34). World Scientific.

[58] Batet, M., Moreno, A., Sánchez, D., Isern, D., \& Valls, A (2012). Turist@: Agent-based personalised recommendation of tourist activities. Expert Systems with Applications, 39(8), 7319-7329.

[59] Noguera, J. M., Barranco, M. J., Segura, R. J., \& Martínez, L. (2012). A mobile 3D-GIS hybrid recommender system for tourism. Information Sciences, 215, 37-52.

[60] Biancalana, C., Gasparetti, F., Micarelli, A., \& Sansonetti, G. (2013). An approach to social recommendation for contextaware mobile services. ACM Transactions on Intelligent Systems and Technology (TIST), 4(1), 10.

[61] Knoch, S., Chapko, A., Emrich, A., Werth, D., \& Loos, P. (2012, September). A Context-Aware Running Route Recommender Learning from User Histories Using Artificial Neural Networks. In Database and Expert Systems Applications (DEXA), 2012 23rd International Workshop on (pp. 106-110). IEEE.

[62] Tsai, C. Y., \& Lai, B. H. (2013, July). A Customized Visiting Route Service under RFID Environment. In Computer Software and Applications Conference Workshops (COMPSACW), 2013 IEEE 37th Annual (pp. 397-402). IEEE.

[63] Sasaki, W., \& Takama, Y. (2013, December). Walking Route Recommender System Considering SAW Criteria. In Technologies and Applications of Artificial Intelligence (TAAI), 2013 Conference on (pp. 246-251). IEEE.

[64] Yawutthi, S., \& Natwichai, J. (2014, May). An Efficient Indexing for Top-k Query Answering in Location-Based Recommendation System. In Information Science and Applications (ICISA), International Conference, 1-4.

[65] Umanets, A., Ferreira, A., \& Leite, N. (2014). GuideMe-A tourist guide with a recommender system and social interaction. Procedia Technology, 17, 407-414.

[66] Benouaret, I., \& Lenne, D. (2015, October). Personalizing the Museum Experience through Context-Aware Recommendations. In Systems, Man, and Cybernetics (SMC), 2015 IEEE International Conference (pp. 743-748).

[67] Wen-ying, Z., \& Guo-ming, Q. (2013, July). A new framework of a personalized location-based restaurant recommendation system in mobile application. In Management Science and Engineering (ICMSE), 2013 International Conference on (pp. 166-172). IEEE.

[68] Chu, C. H., \& Wu, S. H. (2013, June). A Chinese restaurant recommendation system based on mobile context-aware services. In Mobile Data Management (MDM), 2013 IEEE 14th International Conference on (Vol. 2, pp. 116-118). IEEE.

[69] Meehan, K., Lunney, T., Curran, K., \& McCaughey, A. (2013, March). Context-aware intelligent recommendation system for tourism. In Pervasive Computing and Communications Workshops (PERCOM Workshops), 2013 IEEE International Conference on (pp. 328-331). IEEE.

[70] Jiang, S., Qian, X., Shen, J., Fu, Y., \& Mei, T. (2015). Author Topic Model-Based Collaborative Filtering for Personalized POI Recommendations. Multimedia, 17(6), 907-918.

[71] Tiwari, S., \& Kaushik, S. (2014, July). Information enrichment for tourist spot recommender system using location aware crowdsourcing. In Mobile Data Management (MDM), 2014 IEEE 15th International Conference on (Vol. 2, pp. 11-14). IEEE

[72] Baudisch, P. (1999, May). Joining collaborative and contentbased filtering. In Proceedings of the ACM CHI Workshop on Interacting with Recommender Systems (pp. 1-3).

[73] Savage, N. S., Baranski, M., Chavez, N. E., \& Höllerer, T. (2012). I'm feeling loco: A location based context aware recommendation system. In Advances in Location-Based Services (pp. 37-54). Springer Berlin Heidelberg.

[74] Schafer, J. B., Frankowski, D., Herlocker, J., \& Sen, S. (2007). Collaborative filtering recommender systems. In The adaptive web (pp. 291-324). Springer Berlin Heidelberg.

[75] Ying, J.C., Chen, H. S., Lin, K. W., Lu, E. H.C., Tseng, V.S. Tsai, H.W., \& Lin, S. C. (2014). Semantic trajectory-based high utility item recommendation system. Expert Systems with Applications, 41(10), 4762-4776.

[76] Di Bitonto, P., Laterza, M., Roselli, T., \& Rossano, V. (2010). Multi-criteria retrieval in cultural heritage recommendation systems. In Knowledge-Based and Intelligent Information and Engineering Systems (pp. 64-73). Springer Berlin Heidelberg.

[77] Kwon, H. J., \& Hong, K. S. (2012). Personalized Mobile Social Network System Using Collaborative Filtering. In Computer Applications for Graphics, Grid Computing, and Industrial Environment (pp. 215-221). Springer Berlin Heidelberg.

[78] Riboni, D., \& Bettini, C. (2014, March). Differentiallyprivate release of check-in data for venue recommendation. In Pervasive Computing and Communications (PerCom), 2014 IEEE International Conference on (pp. 190-198). IEEE.

[79] Kenteris, M., Gavalas, D., \& Economou, D. (2011). Mytilene E-guide: a multiplatform mobile application tourist guide exemplar. Multimedia Tools and Applications, 54(2), 241-262.

[80] Arya, A., Ragini, S., Kumar, H., \& Abinaya, G. (2012). A text analysis based seamless framework for predicting human personality traits from social networking sites. International Journal of Information Technology and Computer Science (IJITCS), 4(10), 29.

\section{Authors' Profiles}

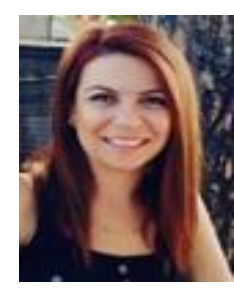

Aysun Bozanta is a $\mathrm{PhD}$ candidate and Research Assistant in the Department of Management Information Systems at Bogazici University, Turkey. She earned M.A. degree from Bogazici University Management Information Systems Department and a B.Sc. double major degree in Management Information Systems Department and Mathematical Engineering Department. Her primary research interests include data analysis techniques, quantitative methods, information systems analysis, design and development.

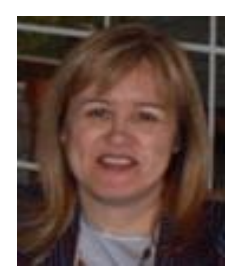

Birgul Kutlu is a Full Professor and Chair of Management Information Systems Department of Bogazici University, Turkey. She teaches several Information Systems and Programming courses at undergraduate and graduate levels. Her primary research interests include elearning, distance education, virtual 
environments, information systems analysis, design and development, neural networks and artificial intelligence.

She has coordinated many B.U. Research Foundation projects as well as European Union and Unesco projects. Dr. Kutlu is the founding member of B.U. Information Systems Research Center, B.U. Tourism Management Research Center and Turkish Informatics Foundation.

How to cite this paper: Aysun Bozanta, Birgul Kutlu,"Current State and Future Trends in Location Recommender Systems", International Journal of Information Technology and Computer Science(IJITCS), Vol.9, No.6, pp.1-8, 2017. DOI: 10.5815/ijitcs.2017.06.01 